\title{
RANDOM STRATEGY VERSUS \\ TECHNICAL ANALYSIS STRATEGY: THE CASE OF EUR/USD INTRADAY TRADING
}

\author{
Miroslav Svoboda ${ }^{1}$ \\ Martina Sponerová ${ }^{2}$
}

Received: November 22, 2019 / Revised: January 3, 2020 / Accepted: February 12, 2020

(C) Association of Economists and Managers of the Balkans, 2020

\begin{abstract}
This paper provides a comparison between the strategy based on technical analysis and the strategy based on random trading on a highly liquid EUR/USD foreign exchange market. The authors analyze three years of data, and in every intraday trading session. Technical analysis strategy uses essential indicators such as moving averages (MA). Every trading position will have the risk-reward ratio (RRR) 3 to 1. In addition, another trading positions on the EUR/USD currency pair will be opened at the same time each day, without technical analysis. The time of entry into position will be indicated by past high liquidity on a given currency pair at a given time with a similar risk-reward ratio (RRR) 3 to 1. This paper aims to compare the strategy of technical analysis and the random strategy in intraday trading concerning the profitability of these trades.
\end{abstract}

Keywords: Investment Decisions, Foreign Exchange Markets, Currency Markets, Moving Average, Backtesting, Intraday Trading.

\section{JEL Classification F13}

This paper was presented at the Third International Scientific Conference on IT, Tourism, Economics, Management and Agriculture - ITEMA 2019 - October 24, Bratislava, Slovakia, www.itema-conference.com

\section{$\bowtie \quad$ Miroslav Svoboda}

svoboda@g-c.cz

$1 \quad$ Masaryk University, Faculty of Economics and Administration, Department of Finance, Lipová 41a, 60300 Brno, Czech Republic

2 Masaryk University, Faculty of Economics and Administration, Department of Finance, Lipová 41a, 60300 Brno, Czech Republic 


\section{INTRODUCTION}

Technical analysis deals with making decisions of investors based on the historical price and other readily available market data. Use of the technical analysis in FX markets has been confirmed by many surveys like Taylor and Allen (1992), Menkhoff (1997), Lui and Mole (1998), Oberlechner (2001), Gehrig and Menkhoff (2004), and Menkhoff and Taylor (2007).

A trading strategy based on technical trading rules that is profitable in the long term is inconsistent with the weak form of the efficient market hypothesis. Some earlier studies supporting the profitability of technical analysis in the foreign exchange markets (Sweeney 1986; Levich and Thomas, 1993; Neely, 1997; LeBaron, 1999, 2002). In theory, the foreign exchange market should be efficient because of very high turnover and domination of professional traders that should not be influenced by the sentiment of retail investors (Sager and Taylor, 2006; Menkhoff and Taylor, 2007).

Some of the recent studies like Hsu and Taylor (2013) and Coakley, Marzano, and Nankervis (2016) analyze technical trading rules of large samples in the foreign exchange market applying stepwise-SPA test. They also include transaction costs and control for data snooping bias, and they found little or no evidence of profitability of these rules. On the other hand, Coakley, Marzano, and Nankervis (2016) found that relatively new trading indicators like Bollinger bands, RSI and MACD remains robustly profitable even after controlling for data snooping bias. Zarrabi, Snaith and Coakley (2017) used FDR analysis and concluded take over 20 years up to $75 \%$ from 7650 trading rules have predictive ability. However, it is necessary to update portfolio at least monthly because no set of trading rules holds for a long time.

The paper aims to test selected strategy based on technical analysis and compare the results with simple random strategy. Authors try to show that on the foreign exchange market the most straightforward strategy is usually able to provide better results than more sophisticated ones, at least in the long term. Moreover, we want to motivate our future research in this field that will use more currency pairs.

The rest of the paper is organized as follows. Section 1 contains methodology and data. Section 2 presents results and discussion, and another section conclusion.

\section{METHODOLOGY AND DATA}

For our research, we use two investing strategies on the forex market (FX). The first strategy (SMA strategy) is based on one of the most popular indicators of technical analysis - Simple Moving Average (SMA). The second strategy (Random strategy) does not use any indicator of technical analysis.

For backtesting, we choose currency pair EUR/USD from 1/2/2015 to 11/11/2019. Risk-reward-ratio (RRR) has been set to 3 to 1 . It means that stop-loss was set to 20 pips under the opening price and target was set to 60 pips above the opening price. We executed both types of orders, such as buy orders and sell orders. We compare two investment strategies, so there is no need to include commissions and spreads. We used a 1 pip fee for a better demonstration. In real trading, our strategies would be less profitable. The fees would be around 1-2 pips per position according to the rules of a particular broker. The following Table 1 shows the basic characteristics of our analysis. 
Table 1. Basic characteristics both strategies

Source: Author's calculations

\begin{tabular}{|c|c|c|}
\hline & Term & Value \\
\hline 1. & - Currency pair & - EUR/USD \\
\hline 2. & - Time frame & $\bullet \mathrm{H} 1$ \\
\hline 3. & - Time period & - $1 / 2 / 2015-11 / 11 / 2019$ \\
\hline 4. & - Spread & $\cdot 1$ pip \\
\hline 5. & - Currency of the account & $\cdot$ USD \\
\hline 6. & - Demonstrative account value & $\cdot 10000$ USD \\
\hline 7. & - RRR & $\cdot 3$ \\
\hline 8. & - Profit (target) & -60 pips \\
\hline 9. & - Loss (stop loss) & - 20 pips \\
\hline 10. & - Time zone & $\cdot \mathrm{UTC}+1$ \\
\hline
\end{tabular}

\subsection{SMA Strategy}

A simple moving average is one of the most popular technical indicators for determining if an asset price will continue or reverse a bull or bear trend. The SMA is calculated as the arithmetic average of an asset's price over some period and determine trend direction. For SMA strategy we use 100 moving period. Our SMA strategy is summarized in the Table 2.

Table 2. Characteristics of SMA strategy

Source: Author's calculations

\begin{tabular}{|c|c|c|}
\hline & Term & Value \\
\hline 1. & - Period of SMA & $\cdot 100$ \\
\hline 2. & - Signal to buy & - First closed candle after candle rise above SMA \\
\hline 3. & - Signal to sell & - First closed candle after candle drops below SMA \\
\hline 4. & - Close position & - Break through stop loss or target \\
\hline
\end{tabular}

The following Figure 1 demonstrate the signal to open the position (sell position in this example) and signal to close the position for our SMA strategy (break through target).

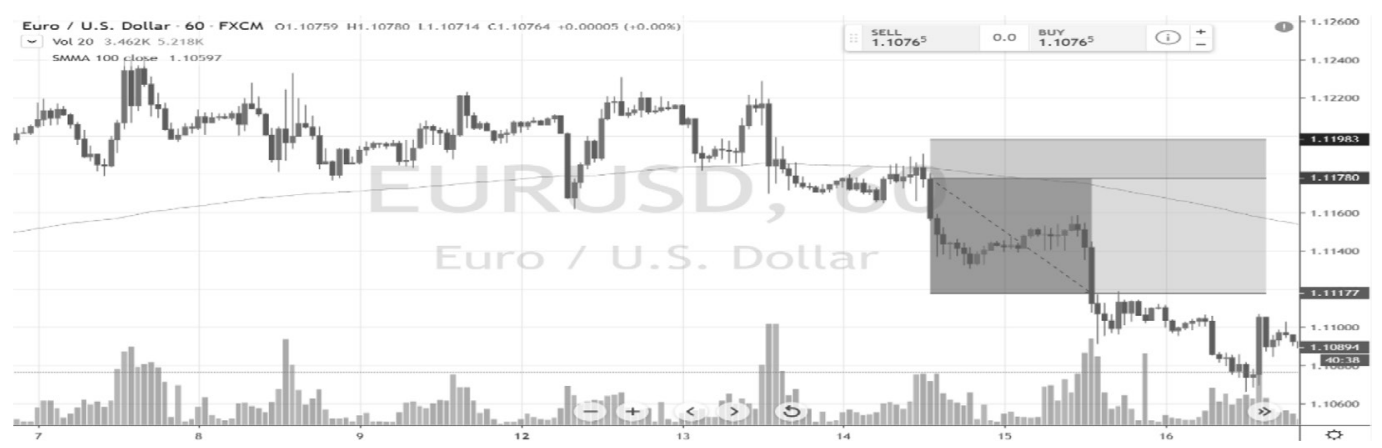

Figure 1. Signal to sell, close position

Source: Author's calculations, tradingview.com

\subsection{Random Strategy}

Our random strategy is based on trading without technical and fundamental analysis. We choose random parameters to enter trading positions. Trading positions are executed at 2 p.m. (UTC 
$+1)$ every trading day (without weekends). The trading hour was selected so that it is close to the opening hour of the US market. That is why we expected a higher rate of currency pair deals. We have entered the sell position and the buy position at random. The Table 3 sums up the rules for opening and closing random strategy.

Table 3. Characteristics of Random strategy

\begin{tabular}{|c|l|l|}
\cline { 2 - 3 } \multicolumn{1}{c|}{} & \multicolumn{1}{c|}{ Term } & \multicolumn{1}{c|}{ Value } \\
\hline 1. & • Period of trading & $\bullet$ Every day, without weekends \\
\hline $\mathbf{2 .}$ & • Signal to buy and sell & $\bullet$ First closed candle after 14:00, UTC +1 (at random) \\
\hline 4. & • Close position & $\bullet$ Break through stop loss or target \\
\hline
\end{tabular}

Source: Author's calculations

The Figure 2 shows an example of opening and closing position according to our random strategy (buy position in this example) and signal to close the position for our random strategy (break through stop loss).

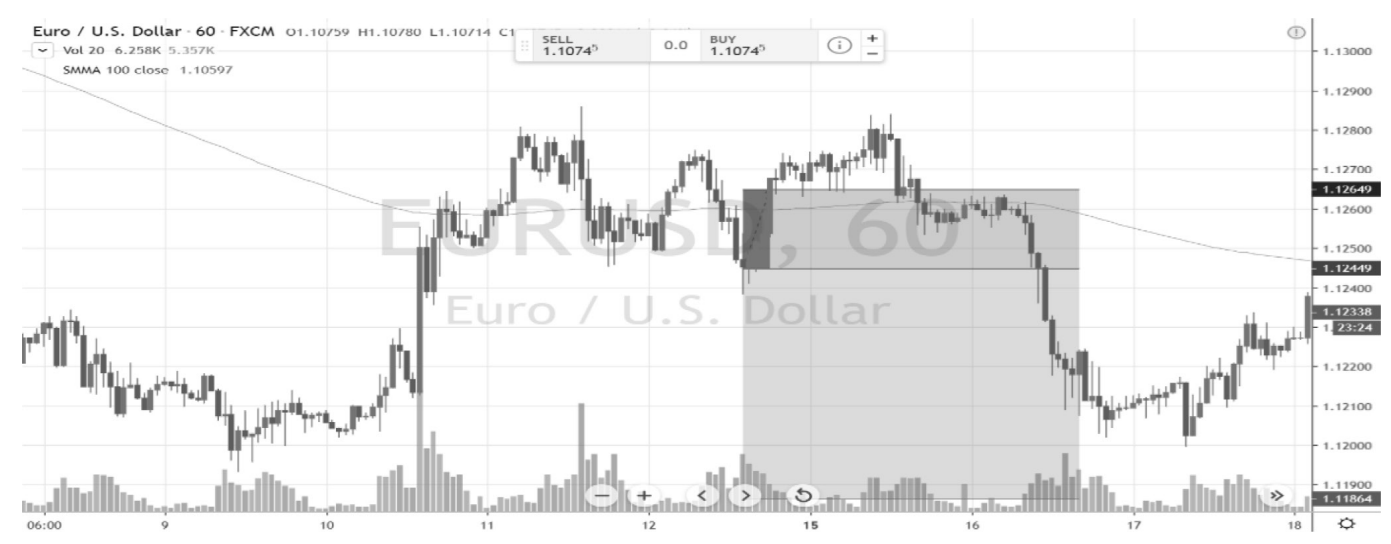

Figure 2. 14:00, UTC + 1, buy position (at random), close position

Source: Author's calculations, tradingview.com

\section{RESULTS AND DISCUSSION}

We use almost 5 years of data and backtest our strategies presented in the previous Chapter 1 . In the Table 4 are our result for both strategies. The random strategy opened one position every trading day, and it resulted in 1261 positions in total. For SMA strategy we have 1299 observations.

Table 4. Results

Source: Author's calculations

\begin{tabular}{|l|l|l|}
\hline & SMA strategy & Random strategy \\
\hline Number of open positions & $\cdot 1299$ & $\cdot 1261$ \\
\hline Number of long positions & $\cdot 647$ & $\cdot 598$ \\
\hline \% of success - long positions & $\cdot 27,51$ & $\cdot 26,76$ \\
\hline Number of short positions & $\cdot 652$ & $\cdot 663$ \\
\hline \% of success - short positions & $\cdot 26,99$ & $\cdot 26,09$ \\
\hline Number of profitable positions (60 pips profit) & $\cdot 354$ & $\cdot 333$ \\
\hline \% of profitable positions (60 pips profit) & $\cdot 27,25$ & $\cdot 26,41$ \\
\hline
\end{tabular}




\begin{tabular}{|l|l|l|}
\hline Number of loss positions (20 pips loss) & $\bullet 945$ & $\cdot 928$ \\
\hline \% of loss positions (20 pips loss) & $\cdot 72,75$ & $\cdot 73,59$ \\
\hline \% total profit & $\cdot 20,92$ & $\cdot 12,95$ \\
\hline Total profit & $\cdot 2091,57$ & $\cdot 1295,43$ \\
\hline
\end{tabular}

The SMA strategy was more profitable in our research. On the other hand, the random strategy also showed a profit balance that approached the SMA strategy. Above we see that it is necessary to set up the right money management. There is a large share of loos positions in the research (72,75\% SMA strategy, 73,59 \% Random strategy), but the right RRR has been able to compensate for losses. Interestingly, both strategies show similar results.

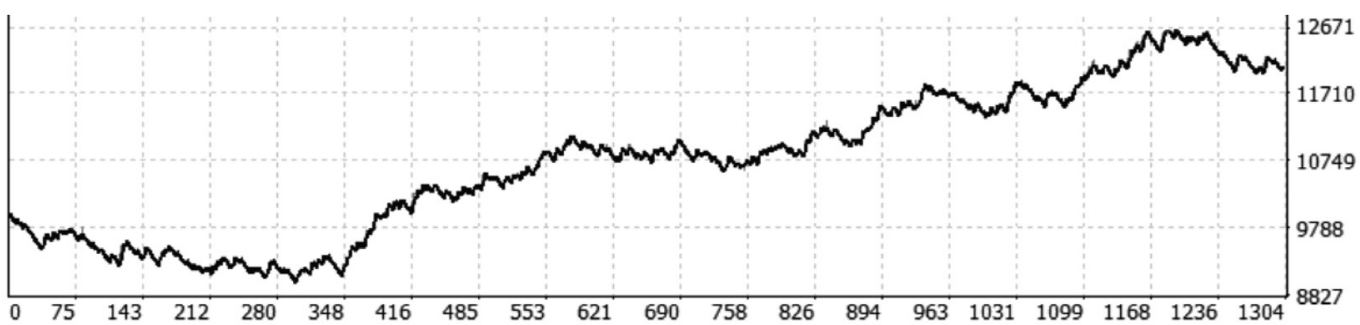

Figure 3. Total profit SMA strategy

Source: Author's calculations, MetaTrader

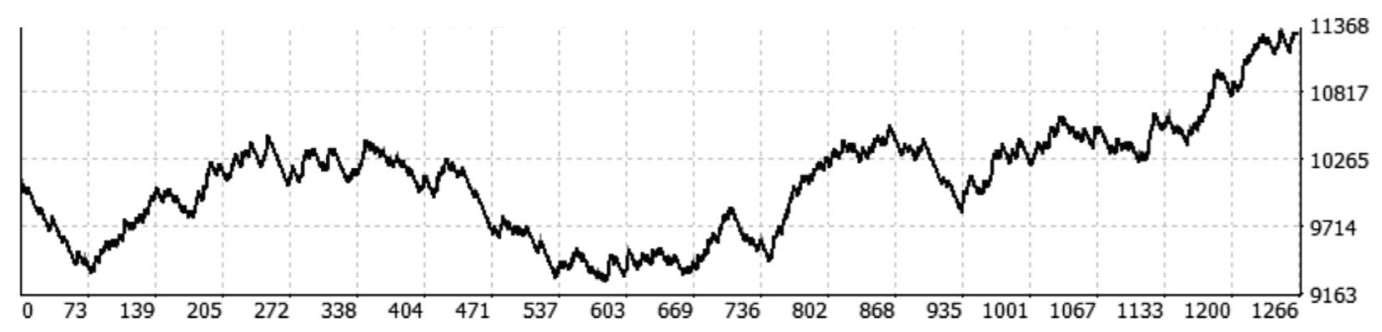

Figure 4. Total profit Random strategy

Source: Author's calculations, MetaTrader

\section{FUTURE RESEARCH DIRECTIONS}

For future research, it is important to answer the question whether the effectiveness of technical analysis is significantly higher than effectiveness of random strategy. Whether it is effective for an investor to develop sophisticated strategies based on technical analysis or set the right risk-reward-ration and run a random strategy. Our results in this paper only suggest, that there is more potential for random strategy and it could be interesting to investigate this issue more deeply with regard to the effectiveness of technical analysis.

\section{CONCLUSION}

In this paper, we compared two trading strategies. The first one uses SMA technical indicator and the second one was randomly opened every day at the same time. We tested both strategies on EUR/USD currency pair for almost five years from 1/2/2015 to 11/11/2019 and set risk-reward-ration to 3 to 1 . 
According to our results, both strategies were profitable with 1 pip spread (fee), but SMA strategy performs a little better. However, it will be the objective of our future research, when we want to focus more on a comparison of simple random trading strategies with more sophisticated trading rules. Our results in this paper only suggest, that there is more potential for random strategy and it could be interesting to investigate this issue more deeply with regard to the effectiveness of technical analysis.

\section{ACKNOWLEDGMENT}

This research was supported by the Masaryk University internal grant MUNI/A/1120/2018.

\section{REFERENCES}

Coakley, J. \& Marzano, M. \& Nankervis, J. (2016). How profitable are FX technical trading rules? International Review of Financial Analysis, vol. 45, pp. 273-282.

Gehrig, T., \& Menkhoff, L. (2004). The use of flow analysis in foreign exchange: Exploratory evidence. Journal of International Money and Finance, vol. 23, pp. 573-594.

Hsu, P. H., \& Taylor, M. P. (2013). Forty years, thirty currencies and 21,000 trading rules: A largescale, data-snooping robust analysis of technical trading in the foreign exchange market. Working paper, thirty currencies and 21.

Laïdi, A. (2008). Currency Trading And Intermarket Analysis. 1nd ed. Wiley Trading, pp. 279.

LeBaron, B. (1999). Technical trading rule profitability and foreign exchange intervention. Journal of International Economics, vol. 49, pp. 125-143.

LeBaron, B. (2002). Technical trading profitability in foreign exchange markets in the 1990s. Working paper, Brandeis University.

Levich, R. M., \& Thomas, L. R. (1993). The significance of technical trading-rule profits in the foreign exchange market: A bootstrap approach. Journal of International Money and Finance, vol. 12 (5), pp. 451-474.

Lui, Y. H., \& Mole, D. (1998). The use of fundamental and technical analysis by foreign exchange dealers: Hong Kong evidence. Journal of International Money and Finance, vol. 17, pp. $535-545$.

Menkhoff, L. (1997). Examining the use of technical currency analysis. International Journal of Finance and Economics, vol. 2(4), pp. 307-318.

Menkhoff, L., \& Taylor, M. P. (2007). The obstinate passion of foreign exchange professionals: Technical analysis. Journal of Economic Literature, vol. 45, pp. 936-972.

Neely, C. J. (1997). Technical analysis in the foreign exchange market: A layman's guide. Federal Reserve Bank of St. Louis Review, vol. 79(5), pp. 23-38.

Oberlechner, T. (2001). Importance of technical and fundamental analysis in the European foreign exchange market. International Journal of Finance and Economics, vol. 6(1), pp. 81-93.

Taylor, M. P., \& Allen, H. (1992). The use of technical analysis in the foreign exchange market. Journal of International Money and Finance, vol. 11, pp. 304-314.

Sager, M. J., \& Taylor, M. P. (2006). Under the microscope: The structure of the foreign exchange market. International Journal of Finance and Economics, vol. 11, pp. 81-95.

Sweeney, R. J. (1986). Beating the foreign exchange market. Journal of Finance, vol. 41(1), pp. 163-182.

Wilder, J. W. (1978). New concepts in technical trading systems. Trend Research, McLeansville, NC.

Zarabi, N. \& Snaith, S. \& Coakley, J. (2017). FX technical trading rules can be profitable sometimes! International Review of Financial Analysis, vol. 49, pp. 113-127. 